\title{
PENGARUH PENGATURAN WAKTU INJEKSI DAN DURASI INJEKSI TERHADAP BRAKE MEAN EFFECTIVE PRESSURE DAN THERMAL EFFICIENCY PADA MESIN DIESEL DUAL FUEL
}

\author{
Ahmad Arif ${ }^{1 *}$, Nuzul Hidayat ${ }^{1}$, M. Yasep Setiawan ${ }^{1}$ \\ ${ }^{1}$ Jurusan Teknik Otomotif, Fakultas Teknik, Universitas Negeri Padang \\ "e-mail: ahmadarif@ft.unp.ac.id
}

\begin{abstract}
Abstrak-CNG merupakan bahan bakar gas yang potensial untuk internal combustion engine karena lebih ekonomis dan ramah lingkungan. Dalam penelitian ini dilakukan pengujian pengaruh pengaturan waktu injeksi dan durasi injeksi CNG terhadap brake mean effective pressure dan thermal efficiency pada mesin diesel dual fuel berbahan bakar solar dan CNG. Penelitian ini dilakukan secara eksperimental dengan menginjeksikan CNG ke intake manifold yang dikontrol ECU. Metode yang digunakan untuk mengetahui nilai pengaturan optimum adalah dengan mapping waktu injeksi dan durasi injeksi CNG melalui software Vemstune pada komputer. Waktu injeksi diatur pada $35^{\circ}, 40^{\circ}$ dan $45^{\circ}$ ATDC dan durasi injeksi sebesar 25, 23 dan 21 ms. Pengujian dilakukan dengan putaran mesin konstan 1500 rpm dan pembebanan dari 500 sampai 4000 watt dengan interval 500 watt. Hasil penelitian menunjukkan bahwa perubahan brake mean effective pressure antara single fuel dan dual fuel relatif kecil karena perubahan arus dan tegangan yang dihasilkan genertor juga kecil. Sedangkan thermal efficiency optimal terdapat pada pengaturan waktu injeksi $35^{\circ}$ ATDC dan durasi injeksi $25 \mathrm{~ms}$, yaitu terjadi penurunan thermal efficiency rata-rata sebanyak 31,51\% daripada single fuel.
\end{abstract}

Kata Kunci : Diesel dual fuel, waktu injeksi, durasi injeksi, brake mean effective pressure, thermal efficiency

\begin{abstract}
CNG is a potential gas fuel for internal combustion engines because it is more economical and environmentally friendly. In this study tested the effect of injection timing and injection duration of CNG to the brake mean effective pressure and thermal efficiency in diesel engine dual fuel diesel and CNG. This experiment was conducted experimentally by injecting CNG into intake manifold controlled by ECU. The method used to determine the optimum setting value is by mapping injection time and injection duration of CNG through Vemstune software on computer. The injection time is set at $35^{\circ}, 40^{\circ}$ and $45^{\circ}$ $A T D C$ and injection duration of 25, 23 and $21 \mathrm{~ms}$. Testing is done with a constant engine speed of 1500 rpm and loading from 500 to 4000 watt with 500 watt interval. The result of this research shows that the brake mean effective pressure between single fuel and dual fuel is relatively small because the current and voltage changes generated by the genertor are also small. While the optimal thermal efficiency are at $35^{\circ}$ ATDC injection timing and injection duration of $25 \mathrm{~ms}$, which is a decline in the average thermal efficiency as much as $31.51 \%$ than the single fuel.
\end{abstract}

Keywords : Diesel dual fuel, injection time, injection duration, brake mean effective pressure, thermal efficiency 


\section{PENDAhUluan}

Compressed natural gas (CNG) merupakan salah satu jenis bahan bakar gas yang paling potensial yang tersedia untuk internal combustion engine karena lebih ekonomis dan ramah lingkungan [1]. Sebuah teknologi yang menjanjikan untuk digunakan pada motor pembakaran dalam adalah sistem dual fuel atau bahan bakar ganda [2]. Mesin diesel dual fuel adalah mesin diesel yang ditambahkan bahan bakar gas pada intake manifold atau langsung ke ruang bakar dan penyalaan pembakaran dilakukan oleh semprotan solar. Saat ini terdapat tiga tipe sistem dual fuel yang digunakan pada mesin diesel, yaitu Low Pressure Injected Gas (LPIG), High Pressure Injected Gas (HPIG) dan Combustion Air Gas Integration (CAGI) [3].

Secara teoritis tipe sistem dual fuel yang lebih efisien digunakan pada adalah Low Pressure Injected Gas (LPIG), karena tipe ini dapat mengurangi potensi gas terbuang karena gas hanya disuplai setelah katup isap terbuka dan katup buang tertutup sehingga penyuplaian bahan bakar gas lebih efisien. Selain itu, tipe ini juga membutuhkan biaya yang lebih murah dibandingkan tipe yang lainnya. Ada beberapa cara yang dapat dilakukan untuk meningkatkan performa mesin diesel dual fuel, diantaranya adalah brake mean effective pressure (tekanan efektif rata-rata) dan thermal efficiency (efisiensi termal). Oleh karena itu, dibutuhkan pengaturan beberapa parameter dalam penyuplaian bahan bakar gas, diantaranya adalah waktu injeksi (injection time) dan durasi injeksi (injection duration) bahan bakar gas. Waktu injeksi sangat menentukan proses pembakaran di dalam selinder sehingga akan mempengaruhi konsumsi bahan bakar yang dihasilkan oleh mesin diesel, termasuk yang menggunakan dual fuel.

Untuk itu, dibutuhkan waktu injeksi yang tepat dalam menginjeksikan bahan bakar ke dalam ruang bakar agar didapatkan pembakaran yang sempurna sehingga akan meningkatkan performa mesin [4]. Adapun durasi injeksi adalah suatu proses lamanya injektor menginjeksikan bahan bakar ke dalam ruang bakar. Lamanya durasi injeksi menentukan jumlah bahan bakar yang disemprotkan ke dalam ruang bakar. Pada bahan bakar gas yang mempunyai nilai density yang rendah maka perlu dilakukan pengaturan durasi injeksi dari keadaan standarnya [5]. Berdasarkan uraian di atas, maka dilakukan pengujian brake mean effective pressure dan thermal efficiency pada mesin diesel dual fuel dengan pengaturan waktu injeksi dan durasi injeksi bahan bakar gas (CNG) sehingga didapatkan pengaturan yang optimal pada setiap kondisi pembebanan mesin.

\section{STUDI PUSTAKA}

\subsection{Bahan Bakar Solar}

Mesin diesel dirancang dengan menggunakan bahan bakar fossil diesel yang diperoleh dari destilasi pendidihan minyak mentah (crude oil) pada suhu $250{ }^{\circ} \mathrm{C}$ sampai $370{ }^{\circ} \mathrm{C}$. Hidrokarbon yang terdapat di dalamnya terdiri dari parafin, naftene, olefin dan aromatic dengan jumlah atom karbon bervariasi mulai 12 sampai 18. Bahan bakar fossil diesel diklasifikasikan menjadi tiga macam, yaitu fossil diesel-1D, yaitu bahan bakar untuk daerah beriklim dingin, fossil diesel-2D, yaitu bahan bakar untuk mesin diesel otomotif dan stasioner putaran menengah keatas serta fossil diesel-4D, yaitu bahan bakar untuk mesin diesel stasioner putaran rendah. Bahan bakar fossil diesel-2D dikenal dengan istilah HSD (High Speed Diesel) [3].

Properties bahan bakar adalah sifat atau karakter yang dimiliki oleh suatu bahan bakar yang terkait dengan performa bahan bakar tersebut dalam proses atomisasi dan pembakaran. Properti umum bahan bakar solar ditunjukkan pada tabel 2.1.

Tabel 2.1 Properties bahan bakar solar [6].

\begin{tabular}{|c|c|c|c|c|}
\hline \multirow{2}{*}{ No. } & \multirow{2}{*}{ Properties } & \multirow{2}{*}{ Unit } & \multicolumn{2}{|c|}{ Limit } \\
\hline & & & Min & $\operatorname{Max}$ \\
\hline 1. & Density $\left(15^{\circ} \mathrm{C}\right)$ & $\mathrm{kg} / \mathrm{m} 3$ & 815 & 870 \\
\hline 2. & Angka Cetane & - & 45 & - \\
\hline 3. & Index Cetane & - & 48 & - \\
\hline 4. & $\begin{array}{l}\text { Visc. Kinematik } \\
\left(40^{\circ} \mathrm{C}\right)\end{array}$ & $\mathrm{mm} 2 / \mathrm{sec}$ & 2.0 & 5.0 \\
\hline 5. & Titik Didih & ${ }^{\circ} \mathrm{C}$ & - & 18 \\
\hline 6. & Titik Nyala & ${ }^{\circ} \mathrm{C}$ & 60 & - \\
\hline 7. & Distilasi: T95 & ${ }^{\circ} \mathrm{C}$ & - & 370 \\
\hline 8. & $\begin{array}{l}\text { Kandungan } \\
\text { Belerang }\end{array}$ & $\%$ massa & - & 0.35 \\
\hline 9. & $\begin{array}{l}\text { Korosi Copper } \\
\text { Residue }\end{array}$ & merit & - & No. 1 \\
\hline 10. & $\begin{array}{l}\text { Konradson } \\
\text { Carbon }\end{array}$ & merit & - & No. 1 \\
\hline 11. & Kandungan Abu & $\% \mathrm{~m} / \mathrm{m}$ & - & 0.01 \\
\hline
\end{tabular}




$\begin{array}{llccc}\text { 12. } & \text { Kandungan Air } & \mathrm{Mg} / \mathrm{kg} & - & 500 \\ \text { 13. } & \text { Partikulat } & \mathrm{Mg} / \mathrm{l} & - & 0.01 \\ \text { 14. } & \text { Angka Asam Kuat } & \mathrm{mgKOH} / \mathrm{g} & - & - \\ \text { 15. } & \text { Total Asam Kuat } & \mathrm{mgKOH} / \mathrm{g} & - & 0.6 \\ \text { 17. } & \text { Warna } & \mathrm{No} . \mathrm{ASTM} & - & 3.0 \\ \text { 18. } & \text { API Gravity } & - & - & -\end{array}$

\subsection{Bahan Bakar Gas}

Bahan bakar gas yang digunakan adalah compressed natural gas (CNG), dimana sebagian besar unsur kimianya terdiri dari methane $\left(\mathrm{CH}_{4}\right)$ dan sisanya berupa ethana, propane, butane, penthane, dan carbon monoxide. Komposisi dan karakteristik dari gas akan sangat bervariasi dari satu sumber dengan sumber lainnya, dimana hal ini mempengaruhi kondisi stoikiometrinya. CNG memiliki beberapa kekurangan, yakni fasenya dalam temperatur ruangan sehingga akan menyulitkan dalam hal penyimpanan dan mobilitas. Selain itu, natural gas memiliki energi persatuan volume (energy density) yang lebih kecil dibandingkan solar, methanol, gasoline, atau bahan bakar hidrokarbon cair lainnya.

CNG merupakan gas alam yang terkompresi yaitu bahan bakar alternatif selain bensin atau solar. Di Indonesia, kita mengenal CNG sebagai bahan bakar gas (BBG). Bahan bakar ini dianggap lebih bersih bila dibandingkan dengan dua bahan bakar minyak karena emisi gas buangnya yang ramah lingkungan. $\mathrm{CNG}$ dibuat dengan melakukan kompresi metana $\left(\mathrm{CH}_{4}\right)$ yang diekstrak dari gas alam. CNG disimpan dan didistribusikan dalam bejana tekan, biasanya berbentuk silinder.

Konversi ke CNG difasilitasi dengan pemberian harga yang lebih murah bila dibandingkan dengan bahan bakar cair (bensin dan solar), peralatan konversi yang dibuat lokal dan infrastruktur distribusi CNG yang terus berkembang [5]. Sejalan dengan semakin meningkatnya harga minyak dan kesadaran lingkungan, CNG saat ini mulai digunakan juga untuk kendaraan penumpang dan truk barang berdaya ringan hingga menengah. Sebenarnya di Indonesia, CNG bukanlah barang baru, pencanangan untuk menggunakan CNG yang harganya lebih murah dan lebih bersih lingkungan daripada bahan bakar minyak sudah dilakukan sejak tahun 1987.
Properti umum CNG ditunjukkan pada tabel 2.2.

Tabel 2.2 Properties CNG [7].

\begin{tabular}{clc}
\hline No. & \multicolumn{1}{c}{ Properties } & Value \\
\hline 1. & Density $\left(\mathrm{kg} / \mathrm{m}^{3}\right)$ & 0,72 \\
2. & Flammability limits $($ volume \% in air) & $4,3-15$ \\
3. & Flammability limits $(\varnothing)$ & $0,4-1,6$ \\
4. & Autoignition temperature in air $\left({ }^{0} \mathrm{C}\right)$ & 723 \\
5. & Minimum ignition energy $(\mathrm{mJ})$ & 0.28 \\
6. & Flame velocity $(\mathrm{ms}-1)$ & 0.38 \\
7. & Adiabatic flame temperature $(\mathrm{K})$ & 2214 \\
8. & Quenching distance $(\mathrm{mm})$ & 2.1 \\
9. & Stoichiometric fuel/air mass ratio & 0.058 \\
10. & Stoichiometric volume fraction $(\%)$ & 9.48 \\
11. & Lower heating value $(\mathrm{MJ} / \mathrm{kg})$ & 45.8 \\
12. & Heat of combustion $(\mathrm{MJ} / \mathrm{kg}$ air $)$ & 2.9
\end{tabular}

\subsection{Mesin Diesel Dual Fuel}

Mesin dual fuel merupakan mesin yang memiliki dua sistem penyuplai bahan bakar yang berbeda dan beroperasi dengan dua jenis bahan bakar secara bersamaan. Mesin dual fuel telah banyak beredar di pasaran yang diaplikasikan pada mesin diesel. Umumnya yang banyak dijumpai adalah sistem dengan bahan bakar solar dan CNG [3]. Dalam sistem ini bahan bakar gas disebut sebagai bahan bakar primer dan bahan bakar solar disebut sebagai bahan bakar sekunder yang bertindak sebagai pilot fuel [8].

Pada sistem single fuel, mesin diesel bekerja dengan mengisap udara murni dari luar. Akan tetapi untuk sistem dual fuel, yang masuk ke dalam ruang bakar tidak hanya udara murni. Udara tersebut akan masuk bersamaan dengan sejumlah bahan bakar gas. Mekanisme pencampuran udara dan bahan bakar gas tersebut dapat terjadi di dalam mixer/blender yang berbentuk venturi atau dengan menggunakan injektor gas yang bertekanan tinggi yang langsung menginjeksikan gas ke ruang bakar, serta menggunakan injektor gas bertekanan rendah yang diletakkan di mulut intake manifold dan hanya akan menginjeksikan gas pada saat katup isap terbuka.

Saat langkah kompresi pada mesin diesel, temperatur dan tekanan campuran udara-bahan bakar gas tersebut akan meningkat. Akan tetapi itu belum cukup untuk membuat campuran tersebut terbakar disebabkan bahan bakar gas memiliki temperatur terbakar sendiri lebih tinggi dibandingkan solar. Oleh sebab itu 
dibutuhkan sejumlah bahan bakar solar yang diinjeksikan ke dalam ruang bakar untuk memulai pembakaran. Pembakaran tersebut akan meningkatkan tekanan dan temperatur dalam ruang bakar, sehingga bahan bakar gas tersebut menjadi terbakar. Metode injeksi solar ke dalam ruang bakar mempertahankan sistem yang asli dari mesin diesel tersebut.

Teknologi sistem dual fuel yang telah digunakan dan dikembangkan pada mesin diesel saat ini tedapat beberapa tipe [2], salah satunya yaitu Low Pressure Injected Gas (LPIG). Tipe ini bekerja dengan melakukan injeksi gas pada saluran isap motor bakar. Proses dilakukan pada tekanan yang cukup rendah, biasanya lebih kecil dari 50 psi.

Sebagaimana halnya mesin diesel yang menggunakan turbocharger, maka tekanan injeksi dari gas harus lebih besar dari tekanan keluaran kompresor-turbocharger (boost pressure). Untuk mesin diesel yang memiliki lebih dari satu silinder ruang bakar, maka dibutuhkan gas injector sebanyak silinder ruang bakar yang dimilikinya.

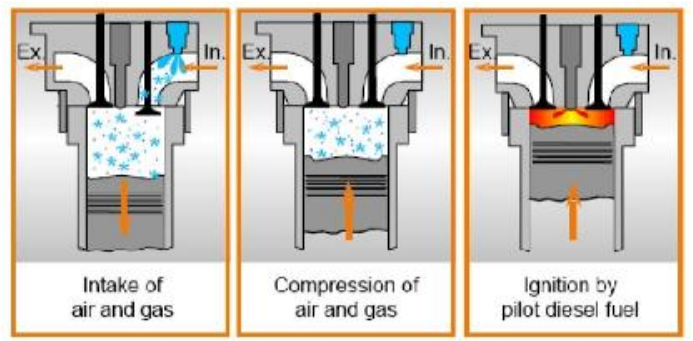

Gambar 2.1 Tipe Low Pressure Injected Gas.

Berdasarkan gambar 2.1 terlihat bahwa fungsi gas injector hanyalah sebagai katup untuk buka tutup aliran gas menuju ruang bakar yang ritmenya diatur berdasarkan timing saat katup isap terbuka. Oleh sebab itu tekanan gas tersebut tidaklah besar.

Keuntungan dari pemakaian sistem ini adalah mengurangi potensi gas terbuang karena gas hanya disuplai pada saat katup isap terbuka, dan sistem ini lebih murah dibandingkan tipe lainnya. Kekurangan dari pemakaian sistem ini adalah sampai sekarang tipe ini hanya cocok digunakan pada mesin diesel dengan putaran rendah. Oleh sebab itu sistem ini digunakan pada aplikasi penggerak kapal dan pemutar generator listrik skala besar.

\subsection{Waktu Injeksi (Injection Time)}

Waktu injeksi (Injection Time) atau Start of injection (awal injeksi) adalah titik awal atau sudut saat penyalaan pembakaran pada mesin diesel dengan jalan menginjeksikan bahan bakar langsung ke dalam ruang bakar (direct injection) atau melalui intake manifold (indirect injection). Waktu injeksi sangat menentukan proses pembakaran di dalam silinder sehingga akan mempengaruhi performa dan emisi gas buang yang dihasilkan oleh mesin diesel termasuk yang menggunakan dual fuel. Untuk itu, dibutuhkan sudut waktu injeksi yang tepat dalam menginjeksikan bahan bakar kedalam ruang bakar agar didapatkan pembakaran yang sempurna sehingga dapat meningkatkan performa dan mengurangi emisi gas buang [4].

\subsection{Durasi Injeksi (Injection Duration)}

Durasi injeksi (injection duration) adalah suatu proses lamanya injektor menginjeksikan bahan bakar ke dalam ruang bakar pada setiap silinder. Lamanya durasi injeksi menentukan jumlah bahan bakar yang diinjeksikan ke dalam ruang bakar dan pada bahan bakar gas (CNG) yang mempunyai nilai density yang rendah, maka perlu dilakukan pengaturan durasi injeksi dari keadaan standarnya. Hal ini dapat meningkatkan performa mesin yang lebih optimal dibandingkan saat menggunakan pengaturan standar CNG [5].

\subsection{Brake Mean Effective Pressure (BMEP)}

Proses pembakaran campuran udara-bahan bakar menghasilkan tekanan (pressure) yang bekerja pada piston sehingga melakukan langkah kerja. Besarnya tekanan ini berubahubah sepanjang langkah piston tersebut. Apabila diambil tekanan yang berharga konstan yang bekerja pada piston dan menghasilkan kerja yang sama, maka tekanan tersebut dikatakan sebagai kerja per siklus per volume langkah piston. Brake mean effective pressure (tekanan efektif rata-rata) secara teoritis yang bekerja sepanjang volume langkah piston sehingga menghasilkan daya yang besarnya sama dengan daya efektif.

$$
\begin{aligned}
\mathrm{BMEP} & =\frac{0,46 \cdot \mathrm{Ne}: \mathbf{z}}{\mathrm{A} \cdot \mathbf{1} \cdot \mathbf{1}: \mathbf{i}}\left(\mathrm{kg} / \mathrm{cm}^{2}\right) \\
\text { dimana: } & \\
\mathrm{Ne} & =\text { daya efektif poros }(\mathrm{hp}) \\
\mathrm{A} & =\text { luas penampang piston }\left(\mathrm{m}^{2}\right) \\
1 & =\text { panjang langkah piston }(\mathrm{m}) \\
\mathrm{i} & =\text { jumlah silinder }
\end{aligned}
$$




$$
\begin{aligned}
\mathrm{n}= & \text { putaran engine }(\mathrm{rpm}) \\
\mathrm{z}= & 1 \text { (motor } 2 \text {-langkah) atau } \\
& 2 \text { (motor 4-langkah) }
\end{aligned}
$$

a. Thermal Efficiency $\left(\eta_{\text {th }}\right)$

Thermal efficiency atau efisiensi termal adalah ukuran besarnya pemanfaatan energi panas yang tersimpan dalam bahan bakar untuk diubah menjadi daya efektif oleh motor pembakaran dalam. Secara teoritis dituliskan dalam persamaan:

Daya efektif yany dihasilkan

'lth $=$ Mass flow rate bahan balkar. Nilaj kalcr bawah bahan bakar

Untuk sistem single fuel dapat ditulis:

$\mathrm{T}_{\mathrm{th}} \mathrm{s}=\frac{\mathrm{Ne}_{\mathrm{g}}}{\mathrm{m}_{\mathrm{s}} \cdot \mathrm{Q}_{\mathrm{s}}} \times 100 \%$

Untuk efisiensi thermal mesin diesel yang menggunakan bahan bakar kombinasi solargas [9], persamaannya adalah:

$\eta_{\text {th d }}=\frac{\mathrm{Ne}_{\mathrm{d}}}{\dot{\mathrm{m}}_{\text {golar }} \mathrm{Q}_{\mathrm{solar}}+\dot{\mathrm{m}}_{\mathrm{CNG}}=\mathrm{Q}_{\mathrm{CNG}}} \times 100 \%$

Dimana Q adalah nilai kalor bawah atau Lower Heating Value (LHV) atau panas pembakaran bawah bahan bakar $[\mathrm{kcal} / \mathrm{kg}$ bahan bakar].

\section{METODE}

Penelitian ini dilakukan dengan menggunakan metode eksperimental. Pengujian dilakukan pada mesin diesel generator set dengan poros utama yang telah terkopel langsung dengan generator listrik. Mesin ini telah dimodifikasi menjadi dual fuel dengan menggunakan bahan bakar solar dan CNG. Metode pengujian pada penelitian ini dibagi atas 2 (dua) kelompok, yaitu: kelompok kontrol, yaitu motor diesel menggunakan single fuel dengan bahan bakar solar dan kelompok uji, adalah motor diesel menggunakan sistem dual fuel dengan bahan bakar kombinasi solar dan CNG.

Mesin diesel generator set yang digunakan sebagai mesin uji adalah mesin diesel 4 (empat) langkah, single cylinder, dengan kapasitas mesin $411 \mathrm{cc}$ dan daya maksimum 6000 watt. Pembebanan yang dilakukan menggunakan beban lampu pijar sebanyak 8 buah dengan konsumsi daya masing-masing lampu sebesar 500 watt. Bahan bakar solar yang digunakan adalah solar yang didapatkan dari pasaran yang diproduksi oleh Pertamina, sedangkan $\mathrm{CNG}$ adalah yang diproduksi oleh PT. PGN.

Proses pemasukan $\mathrm{CNG}$ dengan sistem dual fuel menggunakan tipe LPIG (Low Pressure Injected Gas). Tipe ini bekerja dengan melakukan injeksi CNG pada saluran isap (intake manifold) melalui injektor yang dikontrol menggunakan sistem Electronic Control Unit (ECU). Metode yang digunakan 1oyntuk mengetahui nilai pengaturan optimum adalah dengan mapping waktu injeksi dan durasi injeksi CNG melalui software VEMSTUNE pada komputer. Waktu injeksi yang digunakan adalah $35^{\circ}, 40^{\circ}$ dan $45^{\circ}$ after top dead center (ATDC) dan durasi injeksi sebesar 25, 23 dan $21 \mathrm{~ms}$ (milisecond) serta tekanan CNG yang keluar dari pressure reducer dijaga konstan pada tekanan 2 bar.

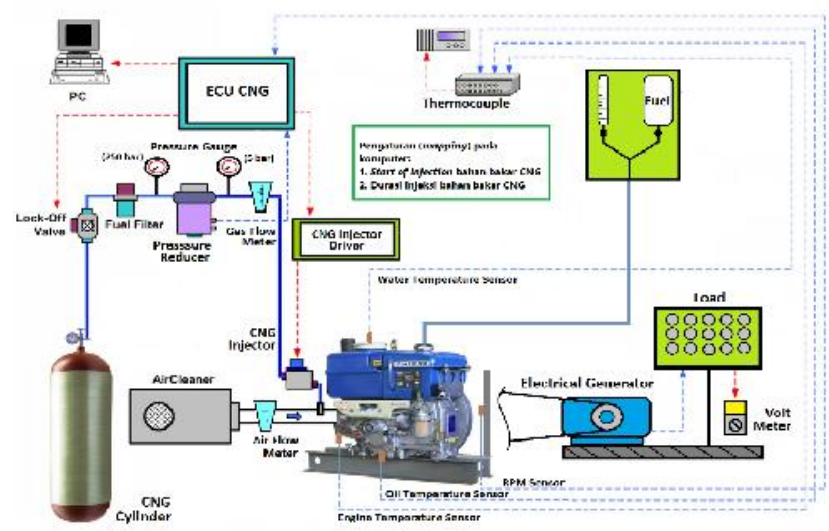

Gambar 3.1 Skema Penelitian

Proses modifikasi mesin dan seluruh rangkaian pengujian dilakukan di Laboratorium Teknik Pembakaran dan Bahan Bakar (TPBB), Jurusan Teknik Mesin, Institut Teknologi Sepuluh Nopember (ITS) Surabaya pada bulan Oktober 2015. Pengujian dilakukan dengan putaran mesin konstan $1500 \mathrm{rpm}$ dan pembebanan bervariasi dari 500 watt sampai 4000 watt dengan interval 500 watt dan setiap tahap pembebanan dilakukan pengambilan data.

Data yang diambil antara lain laju alir udara dan CNG, waktu konsumsi solar setiap $25 \mathrm{ml}$ dan temperatur mesin. Sebelum dilakukan pengujian dengan sistem dual fuel maka terlebih dahulu dilakukan pengujian dengan single fuel solar, hal ini dimaksudkan 
agar didapatkan data awal sebagai acuan/standar guna melihat perubahan parameter-parameter yang terjadi saat penerapan sistem dual fuel.

\section{HASIL DAN PEMBAHASAN}

\subsection{Brake Mean Effective Pressure (BMEP)}

Brake mean effective pressure atau tekanan efektif rata-rata didefinisikan dengan tekanan tetap rata-rata teoritis yang bekerja sepanjang langkah kerja piston. Besarnya tekanan yang dialami piston berubah-ubah sepanjang langkah piston tersebut. Jika diambil tekanan berharga konstan yang bekerja pada piston dan menghasilkan kerja yang sama, maka tekanan tersebut merupakan tekanan efektif rata-rata piston.

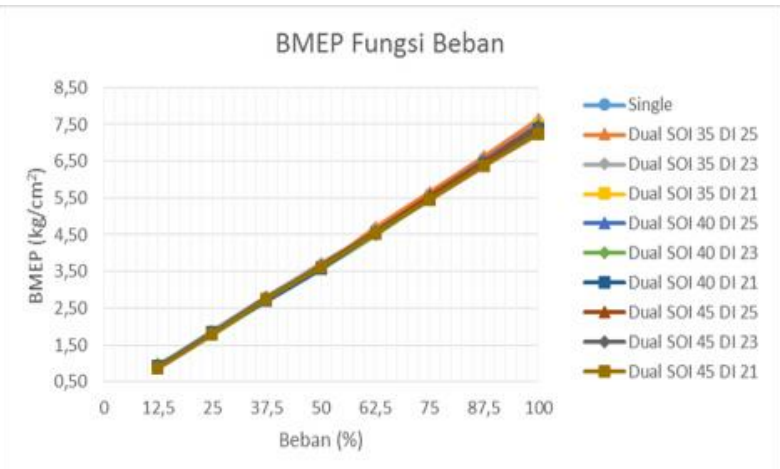

Gambar 4.1 Grafik BMEP fungsi beban

Proses pembakaran campuran udara-bahan bakar menghasilkan tekanan yang bekerja pada piston untuk melakukan langkah kerja. Grafik BMEP terlihat mempunyai kecenderungan naik seiring dengan bertambahnya beban. Apabila ditinjau dari fenomena yang terjadi di dalam mesin, kenaikan beban akan menyebabkan perubahan AFR (air-fuel ratio) ke arah campuran kaya bahan bakar. Semakin banyak bahan bakar yang diledakkan di ruang bakar, maka tekanan ekspansi yang dihasilkan juga akan semakin besar. Hal inilah yang menyebabkan terjadinya kenaikan BMEP seiring dengan kenaikan beban.

Apabila kita generalisir maka bentuk grafik BMEP fungsi beban listrik di atas membentuk garis lurus linier mengikuti bentuk ideal dari grafik BMEP fungsi beban listrik dengan mengabaikan bentuk perbedaan nilai BMEP yang cukup kecil antara masing-masing garis sesuai dengan variasi waktu injeksi dan durasi injeksi CNG. Perubahan tekanan antara dua sistem (single fuel dan dual fuel) relatif kecil, hal ini akibat dari perubahan nilai arus dan tegangan yang dihasilkan oleh genertor juga relatif kecil.

\subsection{Thermal Efficiency $\left(\eta_{t h}\right)$}

Thermal efficiency ( $\eta_{\text {th }}$ ) adalah ukuran besarnya pemanfaatan energi panas yang tersimpan dalam bahan bakar untuk diubah menjadi daya efektif oleh motor pembakaran dalam. Berikut ini adalah grafik thermal efficiency $\left(\eta_{\text {th }}\right)$ terhadap beban saat mesin menggunakan bahan bakar CNG.

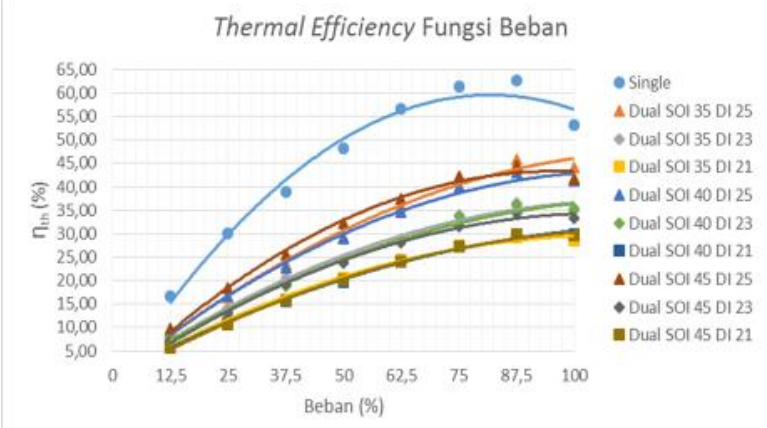

Gambar 4.2 Grafik thermal efficiency fungsi beban

Pada gambar 4.2 terlihat bahwa thermal efficiency tertinggi ada pada penggunaan single fuel, dan kemudian diikuti penurunan nilai efisiensi thermal saat laju aliran massa CNG yang direpresentasikan oleh besarnya durasi injeksi yang dilakukan penambahan. Hal ini disebabkan besar energi input melalui bahan bakar yang masuk ke ruang bakar lebih besar pada dual fuel untuk beban yang sama. Grafik juga menunjukkan bahwa thermal efficiency maksimum berada pada kisaran beban $87,5 \%$, baik untuk single fuel maupun dual fuel.

Dapat dilihat bahwa ada hubungan antara SFC dengan nilai thermal efficiency yang dihasilkan. Saat SFC turun hingga nilai terendah maka thermal efficiency naik hingga bernilai maksimum, yang menggambarkan bahwa dengan naiknya thermal efficiency maka semakin banyak bahan bakar yang dapat dikonversi selama proses pembakaran menjadi daya yang dikeluarkan melalui poros mesin. Saat nilai SFC naik kembali maka nilai thermal efficiency turun yang mengindikasikan semakin banyak bahan bakar yang terbuang berasama gas sisa pembakaran karena tidak 
dapat dikonversi menjadi daya mesin pada saat proses pembakaran berlangsung di ruang bakar.

Dari variasi waktu injeksi dan durasi injeksi masuk bahan bakar CNG menunjukkan thermal efficiency $\left(\eta_{\mathrm{th}}\right)$ terbaik terjadi pada waktu injeksi dengan derajat sebesar $35^{\circ}$ ATDC dan durasi injeksi 25 ms. Dimana penurunan thermal efficiency $\left(\eta_{\mathrm{th}}\right)$ secara ratarata sebanyak $31,51 \%$ terhadap kondisi single fuel. Hal ini menunjukkan bahwa besar derajat injeksi yang optimum untuk menghasilkan efesiensi maksimal ketika menggunakan bahan bakar CNG sebesar $35^{\circ}$ ATDC dan durasi 25 ms. Naiknya thermal efficiency $\left(\eta_{\text {th }}\right)$ seiring dengan waktu injeksi yang dimundurkan dan lamanya durasi injeksi, hal ini disebabkan semakin banyak tersedianya waktu pembakaran dan jumlah bahan bakar CNG sehingga campuran udara-bahan bakar akan terbakar lebih banyak dimana energi hasil pembakaran yang dihasilkan akan lebih besar. Energi hasil pembakaran yang besar juga didapatkan dari laju pembakaran yang cepat karena semakin banyak campuran udara dan bahan bakar yang dapat terbakar maka thermal efficiency $\left(\eta_{\text {th }}\right)$ akan bertambah.

\section{KESIMPULAN}

Berdasarkan hasil penelitian maka dapat disimpulkan sebagai berikut:

1. Perancangan mekanisme pemasukan bahan bakar CNG sistem dual fuel pada mesin diesel Diamond Di 800 single cylinder dilakukan dengan memodifikasi pada saluran intake manifold dan melakukan kalibrasi pada saat awal mesin akan dioperasikan dengan menggunakan bahan bakar dual fuel solar-CNG.

2. Perubahan brake mean effective pressure (BMEP) antara single fuel dan dual fuel relatif kecil karena perubahan arus dan tegangan yang dihasilkan genertor juga kecil. Sedangkan thermal efficiency $\left(\eta_{\mathrm{th}}\right)$ optimal terdapat pada pengaturan waktu injeksi $35^{\circ}$ ATDC dan durasi injeksi $25 \mathrm{~ms}$, yaitu terjadi penurunan thermal efficiency rata-rata sebanyak $31,51 \%$ daripada single fuel.

\section{DAFTAR PUSTAKA}

[1] Lounici, M. Said. Loubar, Khaled.

Tarabet, Lyes. Balistrou, Mourad.

Pengaruh Pengaturan Waktu dan Durasi Injeksi.....(A.Arif et al.)
Niculescu, D. Catalin. and Tazerout, Mohand. (2014). Towards Improvement of Natural Gas-Diesel Dual Fuel Mode: An Experimental Investigation on Performance and Exhaust Emissions, Energi, 64, 200-211.

[2] Korakiantis, T. Namasivayam, A.M \& Crookies, R.J. (2011). Natural-Gas Fueled Spark-Ignition (SI) and Compression-Ignition (CI) Engine Performance and Emissions, Progress in Energy and Combustion Science, 37, 89-112.

[3] Tamam, Zuhri. (2015). Karakterisasi Unjuk Kerja Mesin Diesel Generator Set Sistem Dual Fuel Solar dan Syngas Batubara, Tesis Magister, Institut Teknologi Sepuluh Nopember, Surabaya.

[4] Warsita, Aris. (2012), Pengaruh Injection Timing dan Prosentase Campuran Minyak Diesel dengan Bahan Bakar Biodiesel terhadap Karateristik Mesin dan Emisi Gas Buang, TRAKSI, 12, 1-15.

[5] Aminuddin, Achmad. (2014). Uji Performa Mesin Sinjai Berbahan Bakar Bi-Fuel (Premium-Compressed Natural Gas) dengan Pengaturan Durasi Injeksi dan Air Fuel Ratio, Tesis Magister, Institut Teknologi Sepuluh Nopember, Surabaya.

[6] Kawano, D. Sungkono. (2014), Motor Bakar Torak (Diesel), Jurusan Teknik Mesin FTI-ITS, Surabaya.

[7] Semin and Bakar, A.R. (2008), "A Technical Review of Compressed Natural Gas as an Alternative Fuel for Internal Combustion Engines". American J. of Engineering and Applied Sciences 1, hal.302-311.

[8] Bedoya, I. D., Arrieta, A.A. and Cadavid, F.J. (2009), "Effects of mixing system and pilot fuel quality on dieselebiogas dual fuel engine performance", Bioresour Technol, Vol.100, hal.6624-6629.

[9] Tippawong, N.A., Promwungkwa, P. and Rerkkriangkrai (2006), Long-term Operation of A Small Biogas/Diesel Dual Fuel Engine for On-farm Electricity Generation, Chiang Mai University, Thailand. 


\section{Biodata Penulis}

Ahmad Arif, lahir di Padang Panjang, 27 Februari 1989. Sarjana Pendidikan di Jurusan Teknik Otomotif FT UNP 2012. Tahun 2015 memperoleh gelar Magister Teknik di Program Studi Rekayasa Konversi Energi Jurusan Teknik Mesin Program Pascasarjana ITS Surabaya. Staf pengajar di Jurusan Teknik Otomotif FT UNP sejak tahun 2015 sekarang.

Nuzul Hidayat, Sarjana Pendidikan di Jurusan Teknik Otomotif FT UNP. Dan memperoleh gelar Magister Teknik di Jurusan Teknik Mesin Program Pascasarjana ITS Surabaya. Saat ini aktif sebagai staf pengajar di Jurusan Teknik Otomotif FT UNP.

M Yasep Setiawan, Sarjana Pendidikan di Jurusan Teknik Otomotif FT UNP. Dan memperoleh gelar Magister Teknik di Jurusan Teknik Mesin Program Pascasarjana ITS Surabaya. Saat ini aktif sebagai staf pengajar di Jurusan Teknik Otomotif FT UNP. 